\title{
SECAGEM E ARMAZENAMENTO DE SEMENTES DE Eugenia brasiliensis LAM. (GRUMIXAMEIRA) ${ }^{1}$
}

\author{
SUELI KOHAMA² , ANGELAMARIAMALUF³ ${ }^{2}$ DENISEAUGUSTACAMARGO BILIA ${ }^{4}$, CLAUDIO JOSÉ BARBEDO $^{5}$
}

\begin{abstract}
RESUMO - Há grande demanda por pesquisas com espécies arbóreas nativas do Brasil, principalmente quanto à qualidade fisiológica de suas sementes. Visando avaliar o grau de tolerância à dessecação e a capacidade de armazenamento das sementes de grumixameira (Eugenia brasiliensis), frutos maduros foram coletados em Mogi-Guaçu, SP. Após a colheita, as sementes foram extraídas, lavadas e secas a $36^{\circ} \mathrm{C}$, reduzindo seu teor de água inicial de $48,9 \%$ (base úmida) para até 23,6\% (última secagem), totalizando cinco níveis de secagem. Amostras de sementes de cada nível de secagem foram armazenadas em sacos plásticos, a $7^{\circ} \mathrm{C}$, até 270 dias. Os resultados mostraram que a redução do teor de água para valores inferiores a $43,1 \%$ prejudicou tanto a germinabilidade quanto a capacidade de conservação em armazenamento das sementes. Sementes com 48,9\% de água apresentaram 60\% de germinação após 180 dias de armazenamento e 19\% após 270 dias, quando mantidas em sacos plásticos e em câmara fria. Concluiu-se que sementes de $E$. brasiliensis podem ser armazenadas por 180 dias a $7^{\circ} \mathrm{C}$ e são sensíveis à secagem a $36^{\circ} \mathrm{C}$.
\end{abstract}

Termos para indexação: conservação, dessecação, germinação, Myrtaceae.

\section{DRYINGAND STORAGE OF Eugenia brasiliensis LAM. (“GRUMIXAMEIRA”) SEEDS}

\begin{abstract}
There is an increasing need for investigations of the Brazilian native tree species, mainly the physiological quality of their seeds. To evaluate the desiccation tolerance and storability of Eugenia brasiliensis seeds, mature fruits collected at Mogi-Guaçu, SP, Brazil and their seeds were removed by washing and were dried at $36^{\circ} \mathrm{C}$ until their water content was reduced from $48.9 \%$ (fresh seeds, wet basis) to $23.6 \%$ (final drying), totaling five drying levels. Samples of each drying level were stored at $7^{\circ} \mathrm{C}$ in plastic bags for 270 days. Results showed that water content lower than $43.1 \%$ decreased both germinability [germination potential] and storability. Seeds with $48.9 \%$ water content showed $60 \%$ germination after 180 days and $19 \%$ after 270 days of storage inside plastic bags in a cold chamber. We concluded that E. brasiliensis seeds can be stored for 180 days at $7^{\circ} \mathrm{C}$ and are intolerant to drying at $36^{\circ} \mathrm{C}$.
\end{abstract}

Index terms: conservation, desiccation, germination, Myrtaceae.

\section{INTRODUÇ̃̃O}

O Brasil possui considerável área de mata nativa com grande variedade de árvores frutíferas ainda pouco estudadas, muitas com potencial de aproveitamento pouco explorado e com falta de estudos que permitam a implantação de pomares comerciais. Na família Myrtaceae encontram-se várias espécies nessa condição, especialmente dentro do gênero

\footnotetext{
${ }^{1}$ Submetido em 08/03/2004; Aceito para publicação em 02/06/2005;

${ }^{2}$ Bióloga, ex-bolsista PIBIC/CNPq;

${ }^{3,4}$ Eng. Agrônomo, Dr., Pesquisador do Instituto de Botânica, Caixa Postal
}

Eugenia (Bülow et al., 1994). Apesar de alguns estudos já desenvolvidos visando à conservação da viabilidade de sementes de espécies desse gênero (Rizzini, 1970; Bülow et al., 1994; Barbedo et al., 1998; Anjos e Ferraz, 1999; Gentil e Ferreira, 1999; Maluf et al., 2003), muitas ainda não apresentam tecnologia que permita seu armazenamento por períodos prolongados (Lorenzi, 1992, 2002).

A qualidade inicial das sementes, entendida como

4005, São Paulo, SP, CEP 01061-970. ammaluf@terra.com.br; denisebilia@terra.com.br;

${ }^{5}$ Eng. Agrônomo, Dr., bolsista Produtividade CNPq, Pesquisador do Instituto de Botânica. cjbarbedo@yahoo.com.br. Autor para correspondência. 
intrínseca às mesmas por ocasião de sua colheita, deve ser preservada, tanto quanto possível, até que sejam utilizadas para semeadura (Carneiro e Aguiar, 1993). A preservação da qualidade fisiológica das sementes é fundamental para a manutenção dos bancos de germoplasma e no processo de repovoamento da vegetação em áreas degradadas, pois permite o uso de espécies vegetais em épocas e locais diferentes aos de sua origem.

Diversas técnicas são, com freqüência, estudadas em busca de melhores condições de armazenamento, sendo que a principal técnica de conservação de sementes durante o armazenamento é, ainda, a redução do seu metabolismo, seja através da remoção da água ou da diminuição da temperatura. Contudo, várias espécies tropicais, principalmente arbóreas nativas do Brasil, são intolerantes à dessecação aos níveis desejáveis para conservação em armazenamento, o que requer o desenvolvimento de tecnologias específicas para sua conservação.

Sementes de grumixameira (Eugenia brasiliensis Lam., Myrtaceae) são consideradas de curta longevidade, sendo recomendada sua semeadura imediatamente após sua coleta (Lorenzi, 1992). Contudo, não há estudos científicos que avaliem o grau de sensibilidade dessas sementes à dessecação ou, ainda, às baixas temperaturas.

A grumixameira ocorre nas regiões da mata litorânea do Brasil, desde o sul da Bahia até Santa Catarina. Possui folhas grandes e coriáceas, flores com ovário liso, florescendo a partir do final do mês de setembro até novembro, com amadurecimento dos frutos em novembro e dezembro. As árvores apresentam boas características para o paisagismo, devido ao pequeno porte e forma estreita da copa. Os frutos, amarelos ou pretos, são saborosos, com bom potencial tanto para consumo in natura quanto para a industrialização. Esta característica é interessante, também, para seu uso em reflorestamentos heterogêneos, pois facilita a recuperação da avifauna (Lorenzi, 1992).

Considerando a dificuldade atual em se conservar a viabilidade das sementes de grumixameira durante seu armazenamento, no presente trabalho visou-se avaliar o grau de tolerância à dessecação dessas sementes e à ampliação da sua capacidade de armazenamento através da secagem e da redução da temperatura.

\section{MATERIAL E MÉTODOS}

Obtenção e beneficiamento do material vegetal Frutos de grumixameira (Eugenia brasiliensis Lam.), de dois biótipos (frutos amarelos e frutos roxos), foram coletados de árvores plantadas em pomar na Reserva Biológica e Estação Experimental de Moji-Guaçu, SP (22 $\left.{ }^{\circ} 15-16^{\prime} \mathrm{S}, 4^{\circ} 8-12^{\prime} \mathrm{W}\right)$, apresentando coloração totalmente amarelo intenso e roxa escura, respectivamente para aqueles dois biótipos.

Após as coletas, os frutos foram transportados ao Laboratório da Seção de Sementes e Melhoramento Vegetal, do Instituto de Botânica, em São Paulo. A extração das sementes foi feita manualmente com auxílio de peneira e água corrente. Após a lavagem, as sementes foram colocadas sobre papel filtro por 12 horas para retirar o excesso de água e, então, submetidas a pré-seleção dos lotes, visando à padronização de tamanho das sementes, por meio de peneira de crivo circular de $7 \mathrm{~mm}$, utilizando-se apenas as sementes retidas.

Avaliação da qualidade das sementes - Para determinação do teor de água, foram tomadas quatro repetições com 20 sementes cada, sendo utilizado o método da estufa a $105 \pm 3^{\circ} \mathrm{C}$, durante 24 horas (Brasil, 1992). Os resultados foram expressos em porcentagem, em base úmida.

O teste de germinação foi realizado em câmaras incubadoras BOD, reguladas para temperatura constante de $30^{\circ} \mathrm{C}$ e regime de 12 horas diárias de luz. As sementes foram acondicionadas em rolos de papel (Brasil, 1992), umedecidos com água destilada até o limite de saturação. Foram instaladas quatro repetições de 20 sementes. A germinação foi avaliada aos 30 e aos 45 dias, registrando-se as sementes com protrusão de raiz primária (sementes germináveis) e as plântulas normais (germinação), estas caracterizadas pela presença de raiz primária desenvolvida e parte aérea proporcional ao tamanho da raiz primária, ambas sem defeitos aparentes, produzidas a partir de cada semente. Com estas avaliações obtiveram-se, respectivamente, as porcentagens de sementes germináveis (somatória das sementes que emitiram raiz primária até a última avaliação), de germinação (plântulas normais obtidas até a última avaliação) e da primeira contagem da germinação (plântulas normais obtidas na avaliação aos 30 dias).

A condutividade elétrica da solução de embebição (CESE) das sementes foi avaliada por meio de quatro repetições de 20 sementes, pesadas e colocadas em copos plásticos contendo $75 \mathrm{~mL}$ de água destilada e deionizada, mantidas em câmaras tipo BOD a $25 \pm 1^{\circ} \mathrm{C}$ por 24 horas. Após esse período, a condutividade elétrica da solução foi medida em condutivímetro de bancada para soluções aquosas modelo CA-150, com medidor tipo caneta e faixa de leitura de 0 a $20.000 \mathrm{mS}$ em quatro escalas. Os resultados foram divididos pelo peso inicial das amostras de sementes e expressos em 
$\mathrm{mS} \cdot \mathrm{g}^{-1} \cdot \mathrm{cm}^{-1}$.

Secagem das sementes - As amostras das sementes retiradas de cada lote inicial (lote do biótipo de frutos amarelos e do biótipo de frutos roxos) foram denominadas "controle" e o restante de cada lote foi submetido a secagem em estufa com circulação forçada de ar, regulada para $36 \pm 2^{\circ} \mathrm{C}$, para reduzir o teor de água das sementes para valores próximos a $40,35,30$ e $25 \%$, denominados níveis de secagem. Uma amostra de cada lote foi utilizada para controle da perda de peso e cálculo do teor de água provável do lote ao longo da secagem. Os tempos necessários para atingir valores aproximados àqueles teores de água foram, respectivamente, 20, 40, 65 e 95 horas.

Armazenamento das sementes - amostras de sementes de cada nível e de cada lote foram armazenadas em sacos plásticos (PVC) perfurados (10 furos de, aproximadamente, $1 \mathrm{~mm}$ cada), em câmara fria $\left(7 \pm 1^{\circ} \mathrm{C}, 45 \pm 7 \%\right.$ UR). Essas sementes foram avaliadas quanto à sua qualidade fisiológica imediatamente após a secagem e aos 45, 90, 180 e 270 dias de armazenamento.

Delineamento experimental e análise estatística Os experimentos foram instalados em delineamento inteiramente casualizado, com quatro repetições, em esquema fatorial 2x5x5 (biótipo $\mathrm{x}$ nível de secagem $\mathrm{x}$ período de armazenamento), exceto para o teor de água das sementes que teve esquema $2 \times 5 \times 4$, em razão da falta de sementes para a avaliação do teor de água no último período de armazenamento (270 dias). Os resultados foram submetidos à análise de variância $(p=0,05)$ e as médias foram comparadas entre si pelo teste de Tukey, com os valores em porcentagem sendo analisados após transformação para arc sen $(\% / 100)^{0,5}$, conforme Steel e Torrie (1980). Os dados de germinação, sementes germináveis e primeira contagem da germinação em função do período de armazenamento foram submetidos à análise de regressão polinomial.

\section{RESULTADOS E DISCUSSÃO}

A análise dos valores obtidos para teor de água de sementes de grumixameira não apresentou interação significativa entre os três fatores. Apenas a interação dupla entre níveis de secagem e períodos de armazenamento foi significativa. Assim, considerou-se que o teor inicial de água das sementes de ambos os biótipos foi 48,9\% (Tabela 1). Esse elevado valor situa-se entre os verificados em sementes de outras espécies de Eugenia nativas do Brasil, tais como $E$. involucrata (61-63\%), conforme Barbedo et al. (1998) e Maluf et al. (2003), E. dysenterica DC (47-53\%), segundo Andrade et al. (2003) e E. stipitata ssp. sororia (58,8\% e 59-66\%), de acordo com Gentil e Ferreira (1999) e Anjos e Ferraz (1999), respectivamente.

O primeiro nível de secagem obtido resultou em teor de água de $43,1 \%$ (Tabela 1), ligeiramente acima do programado (40\%); contudo, o segundo nível resultou em teor de água de $35,1 \%$ (Tabela 1), conforme pretendido. Os dois últimos níveis de secagem resultaram em teores de água de $27,2 \%$ e $23,6 \%$ (Tabela 1), ligeiramente abaixo daqueles pré-estabelecidos (30 e $25 \%$, respectivamente).

O armazenamento em sacos plásticos perfurados, mantidas em câmara fria, permitiu que as sementes apresentassem pequenas variações no teor de água que atingiram após a secagem, sendo de 1,8 pontos percentuais no $4^{\circ}$ nível e de 3,5 pontos percentuais no $2^{\circ}$ nível (Tabela 1 ). Em razão da falta de suficiente quantidade de sementes ao final dos 270 dias de armazenamento, optou-se por não avaliar o teor de água das sementes no último período de armazenamento.

A secagem das sementes de grumixameira à temperatura

TABELA 1. Teor de água (\%) e condutividade elétrica da solução de embebição (CESE, sem armazenamento) de sementes de sementes de dois biótipos de grumixameira (Eugenia brasiliensis Lam.), em função dos níveis de secagem e armazenadas por 0 (inicial), 45, 90 e 180 dias

\begin{tabular}{|c|c|c|c|c|c|}
\hline \multirow{2}{*}{$\begin{array}{l}\text { Níveis de } \\
\text { secagem }\end{array}$} & \multicolumn{4}{|c|}{ Período de armazenamento (dias) } & \multirow{2}{*}{$\begin{array}{c}\text { CESE } \\
\left(\square \mathrm{S} \cdot \mathrm{g}^{-1} \cdot \mathrm{cm}^{-1}\right)\end{array}$} \\
\hline & Zero & 45 & 90 & 180 & \\
\hline \multicolumn{6}{|c|}{ Teor de água (\%) } \\
\hline Controle & $48,9 \mathrm{aAB}$ & $48,3 \mathrm{aB}$ & $49,4 \mathrm{aAB}$ & $51,0 \mathrm{aA}$ & $5,14 \mathrm{a}$ \\
\hline $1^{\circ}$ nível & $43,1 \mathrm{bA}$ & $43,0 \mathrm{bA}$ & $44,3 \mathrm{bA}$ & $45,1 \mathrm{bA}$ & $6,73 \mathrm{a}$ \\
\hline $2^{\circ}$ nível & $35,1 \mathrm{cB}$ & $37,3 \mathrm{cAB}$ & $37,8 \mathrm{cA}$ & $38,6 \mathrm{cA}$ & $11,21 \mathrm{~b}$ \\
\hline $3^{\circ}$ nível & $27,2 \mathrm{dAB}$ & $28,9 \mathrm{dA}$ & $25,5 \mathrm{~dB}$ & $28,9 \mathrm{dA}$ & $17,24 \mathrm{c}$ \\
\hline $4^{\circ}$ nível & $23,6 \mathrm{eA}$ & $22,0 \mathrm{eA}$ & $22,5 \mathrm{eA}$ & $21,8 \mathrm{eA}$ & $20,46 \mathrm{~d}$ \\
\hline CV (\%) & \multicolumn{4}{|c|}{$4,9 \%$} & $37,4 \%$ \\
\hline
\end{tabular}

Médias seguidas pela mesma letra, minúscula na coluna e maiúscula na linha, não diferem entre si pelo teste de Tukey, em nível de probabilidade de 5\%. 
de $36 \pm 2^{\circ} \mathrm{C}$, de maneira geral, prejudicou tanto a capacidade de iniciar a germinação (sementes germináveis) quanto a de produzir plântulas normais (germinação), conforme observado na Tabela 2. As sementes de grumixameira amarela mostraram-se mais sensíveis à primeira redução no teor de água (de 48,9 para 43,1\%) do que as da grumixameira roxa que só apresentaram redução significativa na germinação a partir do segundo nível de secagem, ou seja, quando houve redução do teor de água para valores iguais ou inferiores a $35,1 \%$.

Analisando-se a influência dos níveis de secagem e períodos de armazenamento na germinação (Figura 1) e nas sementes germináveis (Figura 2), verificou-se que, para ambos os biótipos, o prejuízo à qualidade fisiológica das sementes ocorreu imediatamente após a secagem. Tal efeito prejudicial foi evidente a partir do segundo nível de secagem e, então, foi tanto maior quanto mais intensa a secagem, atingindo valores praticamente nulos quando o teor de água atingiu 23,6\% (Tabela 2 e Figura 1). Assim sendo, sementes de grumixameira podem ser classificadas como não anidrobióticas (Hoekstra et al., 2001), ou seja, são intolerantes à dessecação ou a exposição à temperatura de $\mathrm{a} 36 \pm 2^{\circ} \mathrm{C}$ por períodos prolongados causou efeitos fisiológicos prejudiciais.

Sementes de espécies brasileiras de Eugenia apresentamse como sensíveis à secagem, mesmo ao sofrerem pequenas reduções do teor de água. Além dos resultados apresentados neste trabalho, para sementes de grumixameira de dois biótipos (roxo e amarelo), as sementes de E. involucrata (Barbedo et al., 1998; Maluf et al., 2003), E. dysenterica (Andrade et al., 2003) e E. stipitata ssp. sororia (Gentil e Ferreira, 1999) mostraram também acentuada sensibilidade à secagem.

A redução na capacidade germinativa das sementes com a secagem também foi acompanhada por aumento nos valores de condutividade elétrica da solução de embebição (Tabela 1), para ambos os biótipos, a partir do $1^{\circ}$ nível de secagem nas sementes sem armazenamento. Tal fato sugere que a secagem pode ter danificado a integridade do sistema de membranas celulares, conforme descrito por Vieira (1994). Além disso, os resultados de CESE indicam que esse teste tem potencial para ser utilizado em avaliações rápidas da qualidade das sementes de grumixameira, como demonstrado para sementes de Inga uruguensis (Barbedo e Cicero, 1998).

Embora a germinação das sementes de grumixameira roxa não tenha sido reduzida após o primeiro nível de secagem, os resultados da primeira contagem do teste de germinação evidenciaram que a qualidade fisiológica das sementes foi significativamente prejudicada já nesse nível (Tabela 3), ou seja, ao reduzir o teor de água de 48,9 para 43,1\%. As sementes não submetidas à secagem produziram $52 \%$ de plântulas normais, 30 dias após o início do teste de germinação, porcentagem cerca de uma vez e meia maior que as do primeiro nível de secagem (35\%). Dessa forma, pode-se considerar que o teor de água crítico, entendido como aquele abaixo do qual se inicia a redução da qualidade fisiológica (em sementes não anidrobióticas), seja superior a $43 \%$ para sementes de grumixameira que, segundo observações em sementes de espécies arbóreas tropicais brasileiras (Barbedo et al., 1998; Bilia et al., 1999; Martins et al., 1999; Andrade, 2001; Andrade et al., 2003; Maluf et al., 2003), estaria situado entre os mais elevados.

Por sua vez, o teor de água letal, entendido como aquele mínimo para a manutenção da viabilidade das sementes não anidrobióticas, é inferior a 23,6\% para sementes de grumixameira, uma vez que $8 \%$ das sementes submetidas à secagem até o quarto nível ainda iniciaram a germinação e apresentaram protrusão de raiz primária (dados não apresentados), imediatamente após a secagem. É importante salientar, contudo, que a elevada temperatura de secagem $\left(36 \pm 2^{\circ} \mathrm{C}\right)$ pode ter exercido alguma influência, ainda que tenha sido próxima à recomendada para a secagem de sementes

TABELA 2. Germinação (\%) e sementes germináveis (\%) de grumixameira (Eugenia brasiliensis Lam.), de dois biótipos (amarelo e roxo), submetidas a diferentes níveis de secagem (médias dos cinco períodos de armazenamento)

\begin{tabular}{|c|c|c|c|c|c|}
\hline \multirow{2}{*}{$\begin{array}{l}\text { Níveis de } \\
\text { secagem }\end{array}$} & \multirow{2}{*}{$\begin{array}{c}\text { Teor de água } \\
(\%)\end{array}$} & \multicolumn{2}{|c|}{ Biótipos } & \multicolumn{2}{|c|}{ Biótipos } \\
\hline & & Amarelo & Roxo & Amarelo & Roxo \\
\hline & & \multicolumn{2}{|c|}{ Germinação (\%) } & \multicolumn{2}{|c|}{ Sementes germináveis $(\%)$} \\
\hline Controle & 48,9 & $54 \mathrm{aB}$ & $64 \mathrm{aA}$ & $69 \mathrm{aB}$ & $76 \mathrm{aA}$ \\
\hline $1^{\circ}$ nível & 43,1 & $37 \mathrm{bB}$ & $55 \mathrm{aA}$ & $52 \mathrm{bB}$ & $70 \mathrm{aA}$ \\
\hline $2^{\circ}$ nível & 35,1 & $9 \mathrm{cA}$ & $11 \mathrm{bA}$ & $22 \mathrm{cA}$ & $22 \mathrm{bA}$ \\
\hline $3^{\circ}$ nível & 27,2 & $2 \mathrm{dA}$ & $1 \mathrm{cA}$ & $4 \mathrm{dA}$ & $2 \mathrm{cA}$ \\
\hline $4^{\circ}$ nível & 23,6 & \multirow{2}{*}{\multicolumn{2}{|c|}{$0 \mathrm{cA}$}} & $0 \mathrm{eA}$ & $0 \mathrm{cA}$ \\
\hline $\mathrm{CV}(\%)$ & & & & \multicolumn{2}{|c|}{23,0} \\
\hline
\end{tabular}

Médias seguidas pela mesma letra, minúscula na coluna e maiúscula na linha, não diferem entre si pelo teste de Tukey, em nível de probabilidade de 5\%. 


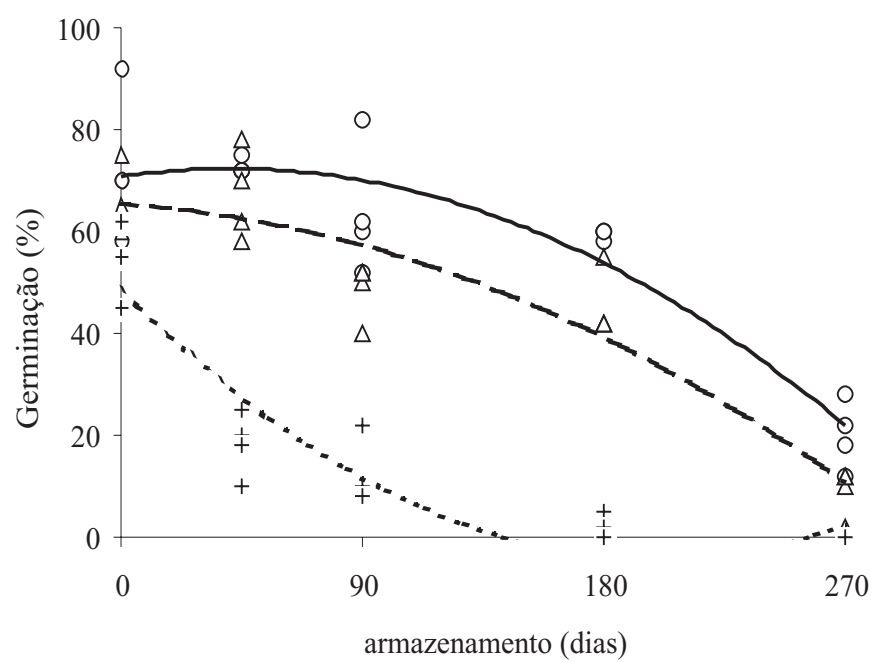

FIGURA 1. Germinação de sementes de grumixameira (Eugenia brasiliensis Lam.), submetidas a diferentes níveis de secagem e armazenadas por 270 dias. Controle (linha contínua, o): $Y=70,754+0,078 X-0,0096 X^{2}$, $\mathbf{r}^{2}=0,83 ; 1^{0}$ nível (linha tracejada, $\left.\ddot{A}\right): Y=65,311-$ $0,032 X-0,0006 X^{2}, r^{2}=0,87 ; 2^{\circ}$ nível (linha pontilhada, + ): $Y=48,578-0,528 X-0,0013 X^{2}, r^{2}=0,87$; $3^{\circ} \mathrm{e} 4^{\circ}$ níveis: valores nulos a partir do primeiro período de armazenamento. Médias dos dois biótipos, Amarelo e Roxo. Coeficiente de variação $=17,63 \%$.

TABELA 3. Primeira contagem do teste de germinação (\%) de sementes de grumixameira (Eugenia brasiliensis Lam.) de dois biótipos (amarelo e roxo), submetidas a diferentes níveis de secagem (médias dos cinco períodos de armazenamento)

\begin{tabular}{ccrc}
\hline Níveis de & Teor de água & \multicolumn{2}{c}{ Biótipos } \\
\cline { 3 - 4 } secagem & $(\%)$ & Amarelo & Roxo \\
\hline Controle & 48,9 & $41 \mathrm{aB}$ & $52 \mathrm{aA}$ \\
$1^{\circ}$ nível & 43,1 & $18 \mathrm{bB}$ & $35 \mathrm{bA}$ \\
$2^{\circ}$ nível & 35,1 & $5 \mathrm{cA}$ & $5 \mathrm{cA}$ \\
$3^{\circ}$ nível & 27,2 & $0 \mathrm{dA}$ & $0 \mathrm{dA}$ \\
$4^{\circ}$ nível & 23,6 & $0 \mathrm{dA}$ & $0 \mathrm{dA}$ \\
\hline CV (\%) & & & 33,6 \\
\hline
\end{tabular}

Médias seguidas pela mesma letra, minúscula na coluna e maiúscula na linha, não diferem entre si pelo teste de Tukey, em nível de probabilidade de 5\%.

com mais de $18 \%$ de água $\left(32^{\circ} \mathrm{C}\right)$, conforme Carvalho e Nakagawa (2000).

A longevidade das sementes de grumixameira em armazenamento é considerada bastante curta e, em razão disso, recomendável a semeadura logo que colhidas (Lorenzi, 1992). Contudo, os resultados obtidos no presente trabalho mostram que, desde que mantidas sob baixa temperatura $\left(7^{\circ} \mathrm{C}\right)$, é possível armazenamento por, no mínimo, seis meses (Figura 1), com $60 \%$ das sementes podendo produzir plântulas normais e por até nove meses (Figuras 1 e 2), com cerca de $30 \%$ das sementes podendo ainda iniciar a germinação e $20 \%$ produzir plântulas normais. Embora estes períodos sejam ainda curtos quando comparados com sementes anidrobióticas longevas, são suficientemente longos para não exigir a semeadura de todo o lote de sementes imediatamente após sua colheita, o que permite o emprego de estratégias de semeadura e armazenamento dos lotes de sementes.

Durante o armazenamento das sementes ficou ainda mais evidente o prejuízo à qualidade fisiológica decorrente das secagens. Se, por um lado, as sementes submetidas ao primeiro nível de secagem não apresentaram reduções expressivas quanto à qualidade fisiológica em relação às não submetidas à secagem, por outro sua capacidade de armazenamento foi prejudicada, principalmente quando analisados os resultados de germinação aos 270 dias (Figura 1) e os de primeira contagem aos 180 dias (Figura 3). É interessante notar que a partir do terceiro nível de secagem, ao reduzir o teor de água de 48,9 para $27,2 \%$ (Tabela 1 ), as sementes perderam a capacidade de conservação da sua viabilidade, apresentando germinação praticamente nula a partir dos primeiros 45 dias de armazenamento. Além disso, mesmo no segundo nível de secagem, com redução do teor de água de 48,9 para $35,1 \%$ (Tabela 1), a germinação foi bastante

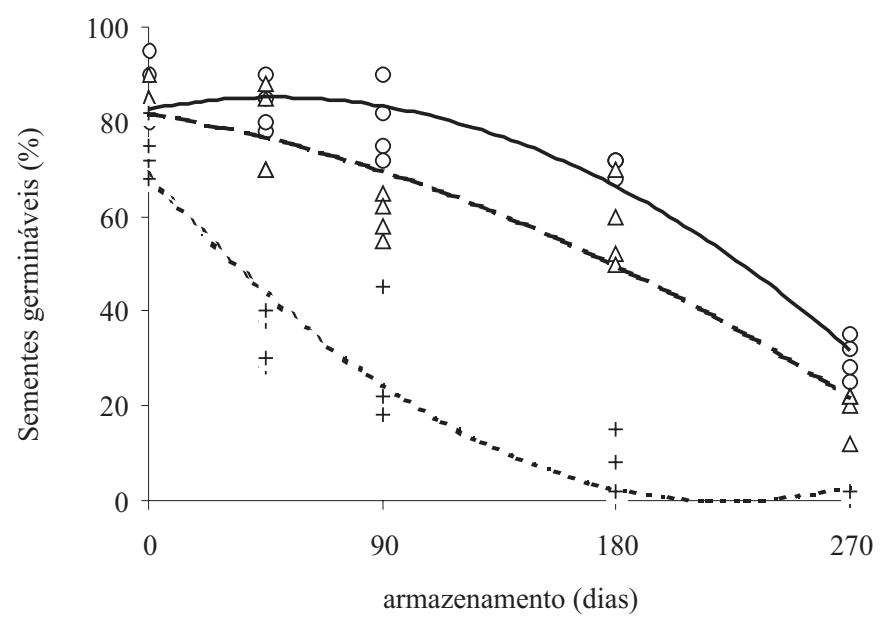

FIGURA 2. Sementes germináveis de grumixameira (Eugenia brasiliensis Lam.), submetidas a diferentes níveis de secagem e armazenadas por 270 dias. Controle (linha contínua, 0 ): $Y=82,632+0,105 X-0,0011 X^{2}$, $\mathbf{r}^{2}=0,91 ; 1^{\circ}$ nível (linha tracejada, $\left.\ddot{A}\right): Y=81,639-$ $0,091 X-0,0005 X^{2}, r^{2}=0,87 ; 2^{\circ}$ nível (linha pontilhada, + ): $Y=68,740-0,616 X-0,0014 X^{2}, r^{2}=0,90$; $3^{\circ} \mathrm{e} 4^{\circ}$ níveis: valores nulos a partir do primeiro período de armazenamento. Médias dos dois biótipos, Amarelo e Roxo. Coeficiente de variação = 13,19\%. 


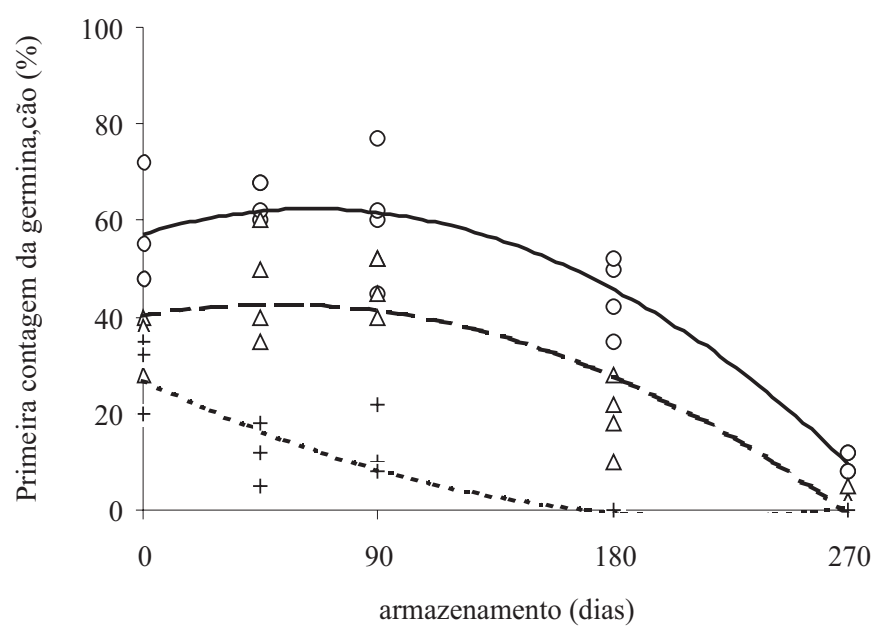

FIGURA 3. Primeira contagem do teste de germinação de sementes de grumixameira (Eugenia brasiliensis Lam.), submetidas a diferentes níveis de secagem e armazenadas por 270 dias. Controle (linha contínua, o): $Y=57,156+0,162 X-0,0012 X^{2}, r^{2}=0,87 ; 1^{\circ}$ nível (linha tracejada, $\ddot{A}$ ): $Y=40,244+0,094 X-0,0009 X^{2}$, $\mathbf{r}^{2}=0,80 ; 2^{\circ}$ nível (linha pontilhada, + ): $Y=26,918$ $0,260 X-0,0006 \mathrm{X}^{2}, \mathrm{r}^{2}=0,77 ; 3^{\circ} \mathrm{e} 4^{\circ}$ níveis: valores nulos a partir do primeiro período de armazenamento. Médias dos dois biótipos, Amarelo e Roxo. Coeficiente de variação $=\mathbf{2 4 , 3 1 \%}$.

reduzida já a partir dos primeiros períodos de armazenamento (Figura 1). Para a obtenção de lotes de sementes, é prática ainda comum, em se tratando de sementes de espécies arbóreas tropicais, recomendar a colheita de frutos logo após a sua queda e, em alguns casos, extrair e expor as sementes ao sol para uma ligeira secagem inicial. Os resultados apresentados no presente trabalho evidenciam que, para sementes de grumixameira, tal prática poderia ser prejudicial à qualidade fisiológica das sementes e, talvez por isso, tais sementes sejam consideradas de curta viabilidade em armazenamento. O prejuízo desta secagem inicial das sementes também foi observado em outras espécies arbóreas tropicais brasileiras (Barbedo et al., 1998; Maluf et al., 2003).

Sementes intolerantes à dessecação, muitas vezes denominadas "recalcitrantes", são freqüentemente consideradas também intolerantes a temperaturas inferiores a $15^{\circ} \mathrm{C}$ (Chin e Roberts, 1980; Ellis, 1984). Pelos resultados obtidos neste trabalho, verifica-se que as sementes de grumixameira, embora intolerantes à dessecação, mantiveram sua capacidade germinativa quando submetidas à temperatura inferior a $15^{\circ} \mathrm{C}$ por períodos prolongados (Figura 1), contrariando o comportamento descrito acima. Deve-se salientar que os estudos com sementes de espécies arbóreas tropicais são relativamente recentes. Porém, há suficiente informação na literatura para que a associação entre intolerância à dessecação e sensibilidade a baixas temperaturas seja questionável. Apenas como exemplos de sementes intolerantes à dessecação que se conservaram bem sob baixa temperatura podem ser citadas as das espécies Inga edulis (Bacchi, 1961), Euterpe espiritosantensis (Martins et al., 2000), Inga uruguensis (Bilia et al., 1999; Barbedo e Cicero, 2000), Eugenia dysenterica (Andrade et al., 2003) e E. involucrata (Barbedo et al., 1998; Maluf et al., 2003).

Finalmente, novos estudos de secagem com diferentes temperaturas são importantes para verificar tanto os efeitos da temperatura elevada quanto os da velocidade de secagem, como os realizados para cerejeira (Eugenia involucrata), por Barbedo et al. (1998) e Maluf et al. (2003), bem como sistemas contínuos e alternados de secagem.

\section{CONCLUSÕES}

Sementes de grumixameira (Eugenia brasiliensis Lam.), com teor de água próximo a 50\%, mantidas em câmara fria a $7^{\circ} \mathrm{C}$, preservam a viabilidade por até 180 dias.

As sementes de grumixameira são sensíveis à secagem a temperatura de $36 \pm 2^{\circ} \mathrm{C}$.

\section{AGRADECIMENTOS}

Aos funcionários da Fazenda Campininha, em MogiGuaçu, pela coleta dos frutos; aos funcionários e estagiários do Laboratório de Sementes do Instituto de Botânica, pelo auxílio nos experimentos; ao CNPq, pelas bolsas de iniciação científica de S. Kohama e de produtividade de C.J. Barbedo; à FAPESP, pelo apoio financeiro ao projeto.

\section{REFERÊNCIAS}

ANDRADE, A.C.S. The effect of moisture content and temperature on the longevity of heart of palm seeds (Euterpe edulis Mart.). Seed Science and Technolgy, Zürich, v.29, n.1, p.171-182, 2001.

ANDRADE, A.C.S.; CUNHA, R.; SOUZA, A.F.; REIS, R.B.; ALMEIDA, K.J. Physiological and morphological savannah tree, Eugenia dysenterica DC. Seed Science and Technolgy, Zürich, v.31, n.1, p.125-137, 2003.

ANJOS, A.M.G.; FERRAZ, I.D.K. Morfologia, germinação e teor de água das sementes de araçá-boi (Eugenia stipitata ssp. sororia). Acta Amazonica, Manaus, v.29, n.3, p.337-348, 1999.

BACCHI, O. Estudos sobre a conservação de sementes. IX - Ingá. Bragantia, Campinas, v.20, n.35, p.805-814, 1961.

BARBEDO, C.J.; CICERO, S.M. Utilização do teste de 
condutividade elétrica para previsão do potencial germinativo de sementes de ingá. Scientia Agricola, Piracicaba, v.55, n.2, p.249259,1998 .

BARBEDO, C.J.; KOHAMA, S.; MALUF, A.M.; BILIA, D.A.C. Germinação e armazenamento de diásporos de cerejeira (Eugenia involucrata DC - Myrtaceae) em função do teor de água. Revista Brasileira de Sementes, Brasília, v.20, n.1, p.184-188, 1998.

BARBEDO, C.J.; CICERO, S.M. The effects of initial quality, low temperature and ABA on the imbibed storage of seeds of Inga uruguensis, a tropical species with recalcitrant seeds. Seed Science and Technology, Zürich, v.28, n.3, p.793-808, 2000.

BILIA, D.A.C.; MARCOS FILHO, J.; NOVEMBRE, A.D.L.C. Desiccation tolerance and seed storability of Inga uruguensis Hook. et Arn. Seed Science and Technology, Zürich, v.27, n.1, p.77-89, 1999.

BRASIL. Ministério da Agricultura e Reforma Agrária. Regras para análise de sementes. Brasília: SNDA/DNDV/CLAV, 1992. $365 \mathrm{p}$.

BÜLOW, J.F.W. VON; CARMONA, R.; PARENTE, T. VAZ. Armazenamento e tratamento de sementes de pitanga-vermelhado-cerrado (Eugenia calycina). Pesquisa Agropecuária Brasileira, Brasília, v.29, n.6, p.961-970, 1994.

CARNEIRO, J.G.A.; AGUIAR, I.B. Armazenamento de sementes. In: AGUIAR, I.B.; PIÑA-RODRIGUES, F.C.M.; FIGLIOLIA, M.B. (Ed.). Sementes florestais tropicais. Brasília: ABRATES, 1993. p.333-350.

CARVAlHO, N.M.; NAKAGAWA, J. Sementes: ciência, tecnologia e produção. 4a ed., Jaboticabal: FUNEP. 2000. 588p.

CHIN, H.F.; ROBERTS, E.H. Recalcitrant crop seeds. Kuala Lumpur: Tropical Press SND, DHDI, 1980.

ELLIS, R.H. The longevity of seeds. Hortscience, Alexandria, v.26, n.9, p.1119-1125, 1991.
GENTIL, D.F.O.; FERREIRA, S.A.N. Viabilidade e superação da dormência em sementes de araçá-boi (Eugenia stipitata ssp. sororia). Acta Amazonica, Manaus, v.29, p.21-31, 1999.

HOEKSTRA, F.A.; GOLOVINA, E.A.; BUITINK, J. Mechanisms of plant desiccation tolerance. Trends in Plant Science, London, v.6, n.9, p. 431-438, 2001.

LORENZI, H. Árvores brasileiras: manual de identificação e cultivo de plantas arbóreas nativas do Brasil. Nova Odessa: Plantarum, 1992. v.1.368p.

LORENZI, H. Árvores brasileiras: manual de identificação e cultivo de plantas arbóreas nativas do Brasil. Nova Odessa: Plantarum, 2002. v.2.368p.

MALUF, A.M.; BILIA, D.A.C.; BARBEDO, C.J. Drying and storage of Eugenia involucrata seeds. Scientia Agricola, Piracicaba, v.60, n.3, p.471-475, 2003.

MARTINS, C.C.; NAKAGAWA, J.; BOVI, M.L.A. Tolerância à dessecação de sementes de palmito-vermelho (Euterpe espiritosantensis Fernandes). Revista Brasileira de Botânica, Brasília, v.22, n.3, p.391-396, 1999.

MARTINS, C.C.; BOVI, M.L.A.; NAKAGAWA, J.; GODOYJÚNIOR, G. Despolpamento e temperatura no armazenamento de sementes de palmito-vermelho (Euterpe espiritosantensis Fernandes). Revista Brasileira de Sementes, São Paulo, v.22, n.1, p.169-176, 2000.

RIZZINI, C.T. Efeito tegumentar na germinação de Eugenia dysenterica DC. (Myrtaceae). Revista Brasileira de Biologia, Rio de Janeiro, v.30, n.3, p.381-402, 1970.

STEEL, R.G.D.; TORRIE, J.H. Principles and procedures of statistics. 2.ed. New York: McGraw Hill, 1980. 481p.

VIEIRA, R.D. Teste de condutividade elétrica. In: VIEIRA, R.D.; CARVALHO, N.M. (Ed.). Testes de vigor em sementes. Jaboticabal: FUNEP, 1994. p.103-132. 